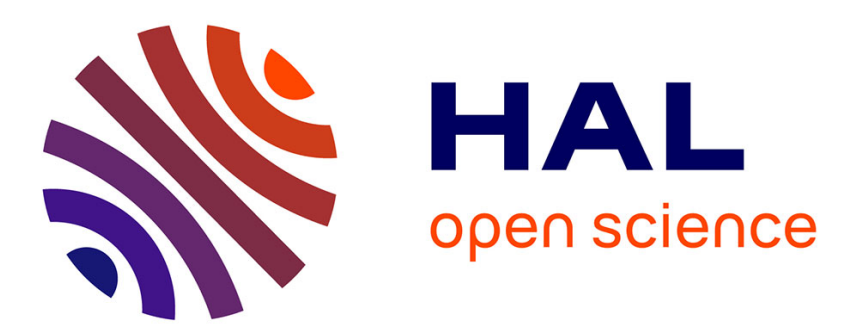

\title{
Erbium-doped transparent glass ceramic optical fibres: Characterization using mass spectroscopy and molecular dynamics modeling
}

Valérie Mauroy, Wilfried Blanc, Christelle Guillermier, Xavier Bidault, Stéphane Chaussedent, Michèle Ude, Stanislaw Trzesien, Bernard Dussardier

\section{- To cite this version:}

Valérie Mauroy, Wilfried Blanc, Christelle Guillermier, Xavier Bidault, Stéphane Chaussedent, et al.. Erbium-doped transparent glass ceramic optical fibres: Characterization using mass spectroscopy and molecular dynamics modeling. 2012 Photonics Global Conference, Dec 2012, Singapore, Singapore. pp.c12a393. hal-00849015

\section{HAL Id: hal-00849015 https://hal.science/hal-00849015}

Submitted on 29 Jul 2013

HAL is a multi-disciplinary open access archive for the deposit and dissemination of scientific research documents, whether they are published or not. The documents may come from teaching and research institutions in France or abroad, or from public or private research centers.
L'archive ouverte pluridisciplinaire HAL, est destinée au dépôt et à la diffusion de documents scientifiques de niveau recherche, publiés ou non, émanant des établissements d'enseignement et de recherche français ou étrangers, des laboratoires publics ou privés. 


\title{
Erbium-doped transparent glass ceramic optical fibres:
}

\author{
Characterization using mass spectroscopy and molecular dynamics modeling.
}

\author{
Valérie Mauroy, Wilfried Blanc, Michèle Ude, \\ Stanislaw Trzesien, Bernard Dussardier \\ Laboratoire de Physique de la Matière Condensée \\ UMR7336 \\ Université Nice-Sophia Antipolis / CNRS \\ Nice, France \\ bernard.dussardier@unice.fr
}

\author{
Christelle Guillermier \\ National Resource for Imaging Mass Spectrometry \\ Harvard Medical School \& Brigham \& Women's Hospital \\ Cambridge, MA, USA
}

\author{
Xavier Bidault, Stéphane Chaussedent \\ Laboratoire de Photonique d'Angers \\ Université d'Angers \\ Angers, France.
}

\begin{abstract}
Rare earth (RE) doped silica-based optical fibres with transparent glass ceramic (TGC) core were fabricated through the well-known modified chemical vapor deposition (MCVD) process without going through the commonly used stage of postceramming. The main characteristics of the RE-doped dielectric nanoparticles (DNP), their density and mean diameter in the fibres are dictated by various parameters. This paper reports on progresses in the fine characterization of the nanopaticles, particularly their dimensions and composition, using nanosclae mass spectroscpy and molecular dynamics modeling, and alteration of the spectroscopic properties of the erbium ions embedded within the phospho-silicate DNP. These results permit to get more insight into the complex process of the DNP selfnucleation and growth during the fibre fabrication process. This fabrication route could have important potentials in improving rare-earth-doped fibre amplifiers and laser sources.
\end{abstract}

Keywordst; Optical fibres, Rare-earth-doped materials; Silica; Spectroscopy, fluorescence and luminescence.

\section{INTRODUCTION}

Developing of new rare-earth (RE)-doped optical fibres for power amplifiers and lasers requires continuous improvements in the fibre spectroscopic properties (like gain and quantum efficiency characteristics, resistance to spectral hole burning and photodarkening,...) besides reduction in device size and economical efficiency. Silica glass as a host material for fibres has proved to be very attractive. However some potential applications of RE-doped fibres suffer from limitations in terms of spectroscopic properties resulting from clustering or inappropriate local environment when doped into silica. The route of interest here consists of using silica as a supporting mechanical host for the fibre optical waveguide, while embedding RE-ions within dielectric (oxide) nanoparticles (DNP). The DNP composition and structure are different fcompared to silica, and they ideally should be small enough to minimize scattering loss down to an acceptable value. The spectroscopic properties or RE-ions in the DNP are expected to be very different from those in silica. We use the term 'Transparent Glass Ceramics' (TGC) for convenience [1], although the DNP may also be amorphous, such as those obtained by phase separation [2]. Scarce reports on RE-doped TGC singlemode fibers used mixed oxides [3], or mixed oxyfluorides [4], both with a subsequent ceramming stage. However their low melting point causes low compatibility with silica components, and the ceramming degrades the fibre strength. Transition metal-doped silica-based TGC fibers were prepared by modified chemical vapour deposition (MCVD) and a slurry doping method [5], i.e. the particles were synthesized before insertion into the silica tube-substrate.

We have proposed a more straightforward technique allowing to embed RE ions within in situ grown oxide DNP in silica-based fibres $[6,7]$, based on the spontaneous phase separation principle: silicate systems can exhibit strong and stable immiscibility when they contain divalent metals oxides (MO, where $\mathrm{M}=\mathrm{Mg}, \mathrm{Ca}$ or $\mathrm{Sr}$ ) [2]. During the manufacture process, the glass decomposes into a silica-rich phase and a MO-rich one in shape of spherical particles. Three key advantages of this process are that (i) DNP are grown in situ, (ii) there is no need (and associated risks) of DNP manipulation by operators and (iii) the process takes advantage of the high compositional control and purity typical of the MCVD technique. Because of the complexity of the fondamental phenomena in action and of the thermal process in manufacturing TGC fibres by MCVD, we study a relatively simple glass system. We have chosen the alkaline-earth 

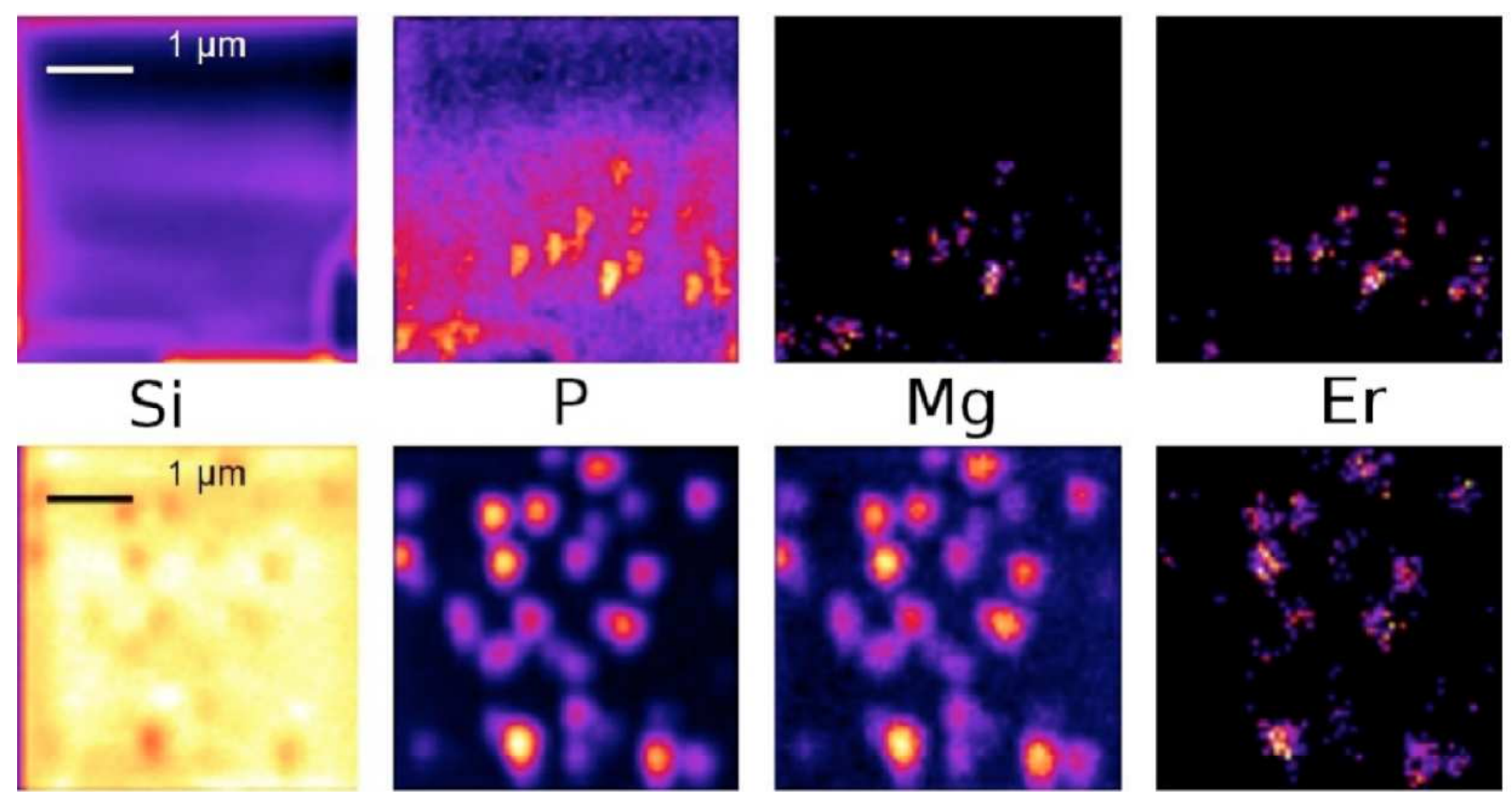

Figure 1. NanoSIMS50 maps of Si, P, Mg and Er in optical fibres. Top/bottom rows are for: $[\mathrm{Mg}]_{\mathrm{sol}}=0.1 / 1.0 \mathrm{~mol} / 1, \mathrm{respectively},[\mathrm{MgO}]_{\text {measured }}=\sim 0.1$ and $1.5 \mathrm{~mol} \%$, respectively

elements series as phase separating agents in order to study the DNP growth dynamics, the resulting composition and structure, and their effects on the spectroscopic properties of the RE-doped TGC fibres. Once the process is better understood, more complex systems may be implemented with applications in mind.

In the present paper, we report further progress in the original characterization of the erbium-doped in situ grown DNP in optical fibres manufactured by MCVD. We had reported that one critical parameter is the concentration of alkaline-earth element in the soaking solution [7,8]. First, the DNP dimension is sensitive to the amount of available alkaline elements. Second, a great broadening of the $1.55-\mu \mathrm{m}$ erbium fluorescence happens when the alkaline-earth concentration is high in the solution. However, it was not yet possible to estimate the actual composition nor structure of the DNP. The aim of this paper is to discuss the nature of the local environment of the RE ions, and the effect on the spectroscopic properties.

For the first time to our knowledge, the qualitative composition mapping of the DNP was performed by NanoSIMS, and shows that RE ions are indeed embedded within the modified silicate DNP. It is shown that phosphorus (P), a common glass homogenizer and softener in MCVD process, is not necessary to form DNP; the phase separation is only ascribable to the divalent $\mathrm{Mg}$ element. Original computations by molecular dynamics (MD) qualitatively back this interpretation. The emission spectroscopy of Er ions is discussed to the light of these findings.

\section{EXPERIMENTAL DETAILS AND RESULTS}

Silica preforms were prepared by the usual MCVD process. Germanium was added during the fabrication to raise the core refractive index. Phosphorus was added in some samples to study its effect on the DNP growth. A detailed description of the technique adapted for DNP growing was reported elsewhere [7]. $\mathrm{Mg}$ and Er elements were incorporated by using the so-called solution doping technique. The final erbium concentration was kept constant at $\sim 300 \mathrm{~mol} \mathrm{ppm}$ (as in erbium-doped fibre amplifiers). The fiber drawing stage has no critical effect on the DNP size distribution [9]. We report on fibres prepared from solutions with $\mathrm{Mg}$ contents $[\mathrm{Mg}]_{\text {sol }}=0.1$ to $1.0 \mathrm{~mol} / \mathrm{litre}$.

The DNP size distributions were analysed from scanning electron microscopy (SEM) images on cleaved fibres $[8,9]$. "Low-Mg" samples typical DNP diameter is $40 \mathrm{~nm}$ in fibres, whereas "high-Mg" DNP are twice as large. In the latter case, high scattering optical loss is observed. For the first time to our knowldege, DNP in fibres were analysed by NanoSIMS at NRIMS [10]. The description of these original measurements on fibres will be reported at the conference. Fig. 1 shows the mapping of all cations for two fibres containing both $0.3 \mathrm{~mol} \%$ of $\mathrm{P}_{2} \mathrm{O}_{5}$ and two different global amount of $\mathrm{Mg}$ (measured by EPMA). The measurements are limited by the resolution of this prototype facility. The room temperature fluorescence around $1.55 \mu \mathrm{m}$ was collected from short fibre samples pumped at 980-nm, and analysed by an optical spectrum analyser (Fig. 2). 
Original molecular dynamics modeling was performed on the binary system $10 \mathrm{MgO}: 90 \mathrm{SiO}_{2}$. The results shown Fig. 3 are obtained from 655360 atoms in a 10-nm side cubic box. They show the system at the end of the fusion stage just before the quenching of the TGC. Here also, additional informations will be provided at the conference.

\section{DISCUSSION}

The NanoSIMS measurements show a remarkable good spatial correlation of elements $\mathrm{P}, \mathrm{Mg}$ and Er, particularly in the "high-Mg" sample. This confirms that all Er ions are embedded within strongly modified silicate DNP, independently of the initial concentration in phase separating element (here $\mathrm{Mg}$ ). The surrounding host is a homogeneous germano-silicate in "high-Mg" samples (the distribution of Ge measured by nanoSIMS, not shown here for the sake of clarity) is homogeneous. The actual composition of the DNP is not yet acccessible because of the limited transverse spatial resolution. Further improvements are under progress. We don't know yet whether the absence of phosphorus in the procees leads to the same drastic partition of elements. The $1.5 \mu \mathrm{m}$ fluorescence spectra in Fig. 2 give some answer: both samples show very similar spectra, whatever phosphorus is present or not. The similarity between spectra indicate that the Er ions are lying in very similar local environment, i.e. in a $\mathrm{Mg}$ rich region of the DNP. The divalent alkaline elements (here : $\mathrm{Mg}$ ) is the only element responsible for the phase separation. Phosphorus has been invoqued as phase separating element by others in silicabased fibres, but only in case of several mol\% of $\mathrm{P}_{2} \mathrm{O}_{5}$.

The preliminary MD modeling results (Fig. 3) suggest indeed that $\mathrm{Mg}$ alone causes phase separation into DNP made either of magnesium-silicate or even pure monocrystalline

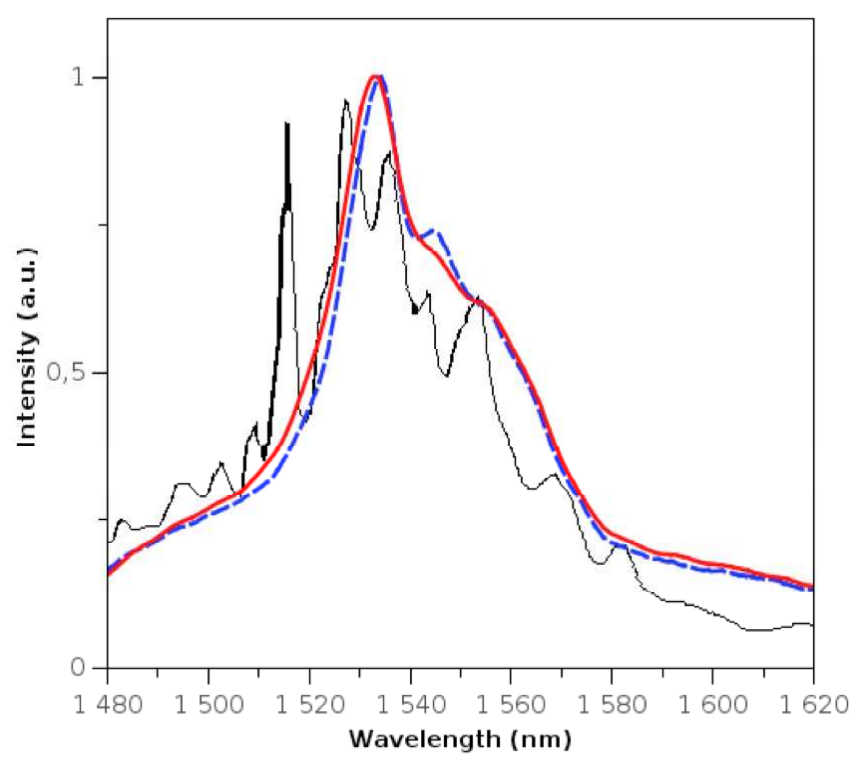

Figure 3. Room temperature emission under 980-nm excitation. Blue dashed line: $[\mathrm{Mg}]_{\mathrm{sol}}=0.5 \mathrm{~mol} / \mathrm{l}$ and no phosphorus. Red solid line: $[\mathrm{Mg}]_{\mathrm{sol}}$ $=1.0 \mathrm{~mol} / 1$ with phosphorus. FWHM $=39.5$ and $42.7 \mathrm{~nm}$, respectively. Resolution: $2 \mathrm{~nm}$. Thin black line: attributed to Er-doped MgSiO3 units, from [11]

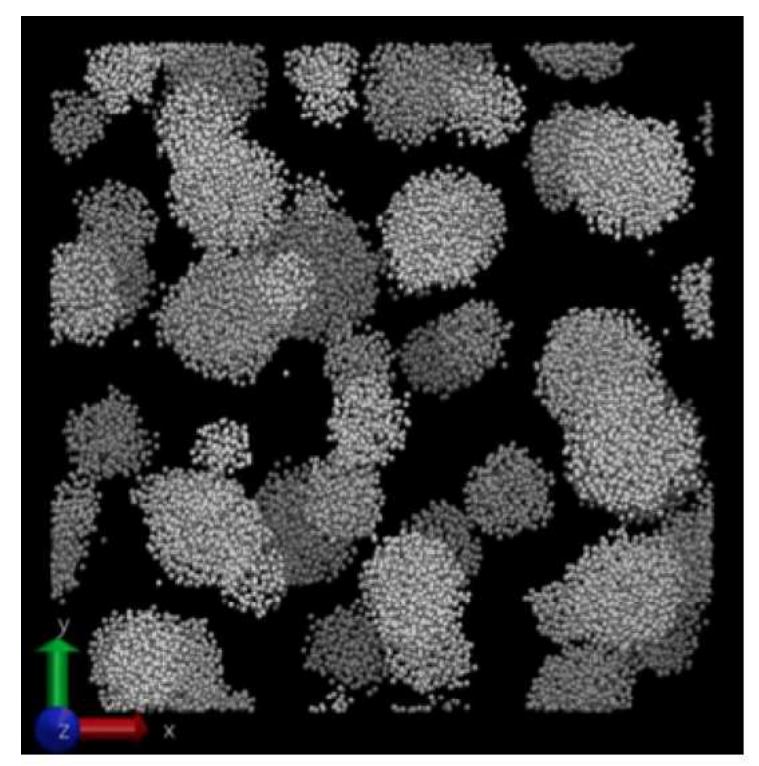

Figure 2. DM simulations on the $10 \mathrm{MgO}: 90 \mathrm{SiO}_{2}$ binary system, at the liquid state, before quenching. Total number of atoms 655360. Only

$\mathrm{Mg}$ are shown. Typical DNP size is $3.7 \mathrm{~nm}(\sim 1400 \mathrm{Mg}$ atoms $)$.

$\mathrm{MgO}$ in some conditions (slow glass quenching). In Fig 2, the spectrum attributed to erbium in crystallized $\mathrm{MgSiO}_{3}$ units by Trento et al. in Ref. 11 has many characteristic peaks, that are not observed in our samples. Therefore we tentatively conclude that in both cases $(\mathrm{Mg}$ only or both $\mathrm{Mg}+\mathrm{P})$, the local environment applied to Er ions are the same, and is amorphous. When $\mathrm{P}$ is present, it does not influence the emission spectra. Further investigations on DNP synthesis and the effects of phosphorus on other spectroscopic properties are under progress and will be discussed at the conference.

\section{CONCLUSION}

We have presented progress in the understanding of the DNP formation in Er-doped TGC optical fibres manufactured entirely by MCVD. The alkaline-earth elements provided in the process are responsible for the phase separation phenomenon which creates the DNP. Additional phosphorus does not have effects on the resulting near-infrared emission spectrum: the same broadening is observed whatever phosphorus is introduced in the core composition. It was shown that the modifying elements are very well separated from the silica host. At last, molecular dynamics modeling on the binary $\mathrm{MgO}: \mathrm{SiO}_{2}$ system conforts our conclusions. At the conference, more details will be provided on the original experimental and numerical tools implemented here, and on the conclusion we draw toward the understanding of the TGC formation. These studies may have great impact in the production of advanced components for photonics applications, including intrinsic gain flattening, spectral hole burning resistance, or irradiation strengthening (to name a few) in future fibre amplifiers and lasers. 


\section{REFERENCES}

[1] M. Clara Gonçalves, L. F. Santos and R. M. Almeida, "Rare-earth-doped transparent glass ceramics," C. R. Chimie, vol. 5, pp. 845-854, 2002.

[2] J. Zarzycki, Glasses and the vitreous state (Cambridge University Press, 1991).

[3] B.N. Samson, L.R. Pinckney, J. Wang, G.H. Beall, N.F. Borrelli, "Nickeldoped nanocrystalline glass-ceramic fiber," Opt. Lett., vol. 27, pp. 13091311, 2002.

[4] B.N. Samson, P.A. Tick, N.F. Borrelli, "Efficient neodymium-doped glass-ceramic fiber laser and amplifier," Opt. Lett., vol. 26, pp. 145-147, 2001.

[5] S. Yoo, U.-C. Paek, W.-T. Han, "Development of a glass optical fiber containing $\mathrm{ZnO}-\mathrm{Al}_{2} \mathrm{O}_{3}-\mathrm{SiO}_{2}$ glass-ceramics doped with $\mathrm{Co}^{2+}$ and its optical absorption characteristics," J. Non-Cryst. Sol., vol. 315, pp. 180186, 2003.

[6] W. Blanc, B. Dussardier, G. Monnom, R. Peretti, A.-M. Jurdyc, B. Jacquier, M. Foret and A. Roberts, "Erbium emission properties in nanostructured fibers," Appl. Opt., vol. 48(31), pp. G119-G124, 2009.
[7] W. Blanc, B. Dussardier and M. C. Paul, "Er-doped oxide nanoparticles in silica-based optical fibers," Glass Technol.: Eur. J. Glass Sci. Technol. A, vol. 50(1), pp. 79-81, 2009.

[8] W. Blanc, V. Mauroy, L. Nguyen, S.N. Bhaktha, P. Sebbah, B. P. Pal and B. Dussardier, "Fabrication of Rare Earth-Doped Transparent Glass Ceramic Optical Fibers by Modified Chemical Vapor Deposition," J. Am. Ceram. Soc., vol. 94(8), pp. 2315-2318, 2011.

[9] V. Mauroy, W. Blanc, M. Ude, S. Trzesien, B. Dussardier, "Growth of rare-earth doped oxyde nanoparticles in silica fibers", 9th Symposium " $\mathrm{SiO}_{2}$ : Advanced Dielectrics and Related Devices" - Hyères France, 1720 June 2012

[10] W. Blanc, C. Guillermier, B. Dussardier, "Composition of nanoparticles in optical fibers by Secondary Ion Mass Spectrometry," Opt. Mater. Express., vol. 2, pp. 1504-1510, 2012).

[11] J. Tronto, S. J. L. Ribeiro, J. B. Valim, et R. R. Gonçalves, "Visible and near-infrared luminescent $\mathrm{Eu}^{3+}$ or $\mathrm{Er}^{3+}$ doped laponite-derived xerogels and thick films: Structural and spectroscopic properties," Materials Chemistry and Physics, vol. 113, pp. 71-77, 2009. 